\title{
Clinical significance of troponin elevations in acute decompensated diabetes without clinical acute coronary syndrome
}

\author{
Anthony Eubanks², Farhan Raza², Mohamad Alkhouli,2, April N Glenn³, Carol Homko ${ }^{1}$, Abul Kashem
} and Alfred Bove ${ }^{1,3^{*}}$

\begin{abstract}
Background: Elevation of cardiac troponin has been documented in multiple settings without acute coronary syndrome. However, its impact on long-term cardiac outcomes in the context of acute decompensated diabetes remains to be explored.

Methods: We performed a retrospective analysis of 872 patients admitted to Temple University Hospital from 2004-2009 with DKA or HHS. Patients were included if they had cardiac troponin I (cTnl) measured within 24 hours of hospital admission, had no evidence of acute coronary syndrome and had a follow up period of at least 18 months. Of the 264 patients who met the criteria, we reviewed the baseline patient characteristics, admission labs, EKGs and major adverse cardiovascular events during the follow up period. Patients were categorized into two groups with normal and elevated levels of cardiac enzymes. The composite end point of the study was the occurrence of a major cardiovascular event (MACE) during the follow up period and was compared between the two groups.

Results: Of 264 patients, 24 patients were found to have elevated cTnl. Compared to patients with normal cardiac enzymes, there was a significant increase in incidence of MACE in patients with elevated cTnl. In a regression analysis, which included prior history of CAD, HTN and ESRD, the only variable that independently predicted MACE was an elevation in $c T n l(p=0.044)$. Patients with elevated CK-MB had increased lengths of hospitalization compared to the other group $(\mathrm{p}<0.001)$.

Conclusions: Elevated cardiac troponin I in patients admitted with decompensated diabetes and without evidence of acute coronary syndrome, strongly correlate with a later major cardiovascular event. Thus, elevated troponin I during metabolic abnormalities identify a group of patients at an increased risk for poor long-term outcomes. Whether these patients may benefit from early detection, risk stratification and preventive interventions remains to be investigated.
\end{abstract}

Keywords: Cardiac troponin-I, Decompensated diabetes, Prognostic markers, Acute coronary syndrome, CK-MB

\footnotetext{
* Correspondence: Alfred.Bove@tuhs.temple.edu

${ }^{1}$ Cardiology Section, Temple University School of Medicine, Philadelphia, USA

${ }^{3}$ Temple University Medical Center - Cardiology Section, 3401 North Broad

Street, Room, Philadelphia, PA19140, USA

Full list of author information is available at the end of the article
} 


\section{Background}

Elevated cardiac biomarkers in decompensated diabetes in the absence of an acute coronary syndrome (ACS) have been described in several case reports [1-5]. While non-ACS related cardiac biomarkers have been studied in various acute and chronic medical conditions, acute decompensated diabetes has received less attention [1,5-12]. Acute decompensated diabetes and ACS, share a complex dynamic that results in significant ambiguity when interpreting biomarker elevation in this setting [13-15]. Such ambiguity is concerning because myocardial infarction has been shown to be the most common cause of death within the first 24 hours of admission for acutely decompensated diabetes [16].

Recent studies have highlighted a novel relationship between the severity of acidemia in acute decompensated diabetes and abnormal elevations in cardiac troponin-I (cTnI). Moller et al. describe patients in diabetic ketoacidosis with severe acidemia and abnormally elevated c'TnI who had no angiographic evidence of coronary artery disease (CAD), leading them to suggest that ketoacidemia may contribute to elevations in cardiac enzymes [4].

Since the number of hospital discharges for acute decompensated diabetes has doubled since 1980 [17] and the worldwide incidence of diabetes mellitus (DM) is expected to double over the next 15 years [18-22], defining the importance of elevated cardiac biomarkers in diabetic disorders is critical. In this study, we assessed the clinical significance of abnormal elevations in cTnI in decompensated diabetics.

\section{Methods}

We performed a retrospective review of 872 charts for patients admitted to Temple University Hospital (TUH) with a diagnosis of "Diabetic Ketoacidemia" between 2004-2009. Approval for this chart review was obtained from the Institutional Review Board. Inclusion criteria required patients to have levels of cTnI within 24 hours of admission, a history of prior or newly diagnosed diabetes mellitus, and evidence of diabetic ketoacidemia (DKA) or the hyperosmolar hyperglycemic state (HHS). DKA and HHS were defined in accord with common clinical practice [14,15]. 298 patients met inclusion criteria.

For patients that met inclusion criteria, if levels of CK$\mathrm{MB}$ were also measured, serum values for both biomarker sub-types were recorded. Patients were considered to have abnormal elevations in cardiac biomarkers if either CKMB (0.00-7.50 ng/ml) or cTnI (0.05-0.40 ng/ml) were above the hospital's normal reference level.

Patients were excluded from the study if they had evidence of acute coronary syndrome in accord with the AHA/ACC Guidelines [18], or if the patient died during the hospitalization. ECGs were analyzed retrospectively by two separate physicians blinded to clinical outcomes. An ECG was determined to be consistent with ACS if there was $\geq 1 \mathrm{~mm}$ ST depression or $\geq 2 \mathrm{~mm}$ ischemic $\mathrm{T}$ wave inversion, new Q- waves, new left bundle branch block, or ST elevations consistent with ischemia. Of the 298 patients who met inclusion criteria, 34 were excluded because of suspected or confirmed ACS, or death during admission (See Figure 1). For the remaining 264 patients,

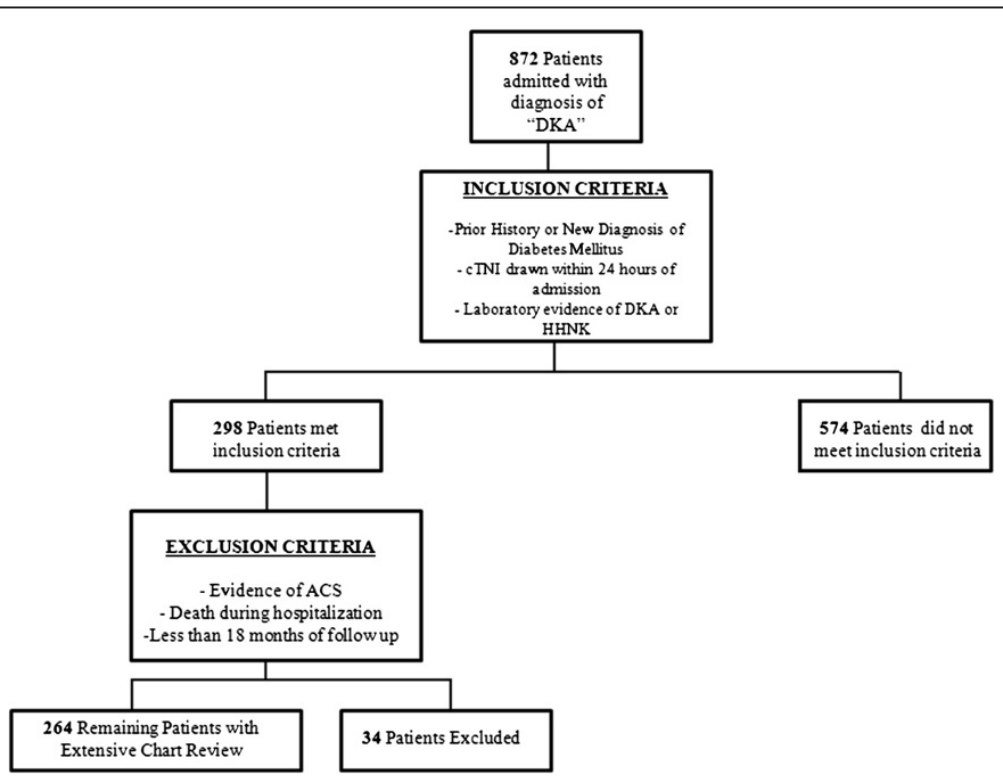

Figure 1 Flow Chart Identifying Patient Selection. Abbreviations: ACS = Acute Coronary Syndrome; DKA = Diabetic Ketoacidosis; HHNK = Hyperglycemic Hyperosmolar Non-Ketotic Syndrome. 
Table 1 Descriptive statistics - continuous data

\begin{tabular}{|c|c|c|c|}
\hline Variable & Normal cTnl & Elevated cTnl & $\mathrm{P}$ value \\
\hline Age(Years) & $45.1 \pm .88$ & $50.3 \pm 3.41$ & .081 \\
\hline \multicolumn{4}{|l|}{ Blood } \\
\hline Glucose (mg/dL) & $690.0 \pm 17.30$ & $1045 \pm 82.30$ & $<0.001$ \\
\hline Hemoglobin (gm/dL) & $14.30 \pm 0.27$ & $12.50 \pm 0.60$ & 0.040 \\
\hline $\mathrm{pH}$ & $7.18 \pm 0.01$ & $7.07 \pm 0.04$ & $<0.001$ \\
\hline Anion Gap (mmol/L) & $26.00 \pm 0.42$ & $28.13 \pm 1.67$ & 0.138 \\
\hline Creatinine $(\mathrm{mg} / \mathrm{dL})$ & $2.40 \pm 0.12$ & $4.22 \pm 0.58$ & 0.004 \\
\hline Mean length of Follow Up (Months) & $41.6 \pm 1.31$ & $37.9 \pm 4.10$ & 0.691 \\
\hline
\end{tabular}

prior medical history, and key hospital data were recorded. Using the electronic medical record, Alpha Imaging Systems $^{\circledR}$, Centricity ${ }^{\circledR}$, PACS $^{\circledR}$ image viewer and EPIC ${ }^{\circledR}$, both inpatient and outpatient medical records were reviewed to record baseline patient characteristics, length of hospital stay, length of follow up, and to assess the time interval in months to the occurrence of a major adverse cardiac event (MACE). MACE was defined as myocardial infarction, percutaneous coronary intervention (PCI), coronary artery bypass grafting (CABG), or death. Only the first admission was included for patients admitted more than once. chronic renal insufficiency was defined as baseline creatinine above $1.4 \mathrm{mg} / \mathrm{dL}$, end stage renal disease (ESRD) was defined as patients on hemodialysis or peritoneal dialysis.

\section{Statistical analysis}

Continuous variables were expressed as mean $\pm \mathrm{SE}$ and statistical significance was tested using the Student $\mathrm{t}$ test. Categorical variables were analyzed using either the chi-square statistic or Fischer exact test, as appropriate. Patients were grouped as normal versus elevated based upon serum admission cTnI levels. Multivariate logistic regression models were constructed to determine variables that predicted abnormal elevations in admission serum cTnI. Similar models were constructed to identify

Table 2 Descriptive statistics - categorical data

\begin{tabular}{lccc}
\hline Variable & Normal cTnl & Elevated cTnl & P value \\
\hline \%Male & 50.0 & 50.0 & .479 \\
\hline White (\%) & 20.5 & 20.8 & .942 \\
\hline Black (\%) & 69.0 & 62.5 & .942 \\
\hline Latino (\%) & 7.9 & 8.3 & .942 \\
\hline Other (\%) & 2.5 & 4.2 & .942 \\
\hline History of CAD (\%) & 4.6 & 41.7 & $<0.001$ \\
\hline CRI (\%) & 9.7 & 12.5 & 0.66 \\
\hline ESRD (\%) & 2.1 & 8.3 & 0.07 \\
\hline Tobacco (\%) & 53.2 & 45.0 & 0.48 \\
\hline HTN (\%) & 45.6 & 69.6 & 0.028 \\
\hline Abbevatins: CAD Coronaty
\end{tabular}

Abbreviations: $\mathrm{CAD}=$ Coronary Artery Disease; $\mathrm{CRI}=$ Chronic Renal Insufficiency; ESRD = End Stage Renal Disease; HTN = Hypertension. variables that independently predicted long term outcomes. Linear regression models were constructed to identify variables that predicted length of hospital stay. Length of hospital stay and MACE were chosen as objective measures for short and long term outcomes respectively. Kaplan-Meir plots were used to assess effects over time. Associations were considered significant if alpha $<0.05$. All analyses were performed with SPSS. v19.0

\section{Measurement of cardiac troponin I}

The blood specimens analyzed in this study were collected in observation with routine precautions for venipuncture. Blood samples were allowed to clot completely prior to centrifugation and stored at room temperature $\left(15\right.$ to $\left.30^{\circ} \mathrm{C}\right)$ for no longer than two hours.

Cardiac troponin I was measured by the Access AccuTni ${ }^{\mathrm{TM}}$ chemiluminescent immunoassay (Beckman Coulter ${ }^{\circledR}$ ). This assay uses two monoclonal antibodies in conjunction with alkaline phosphatase to bind antigenic sites in the solid

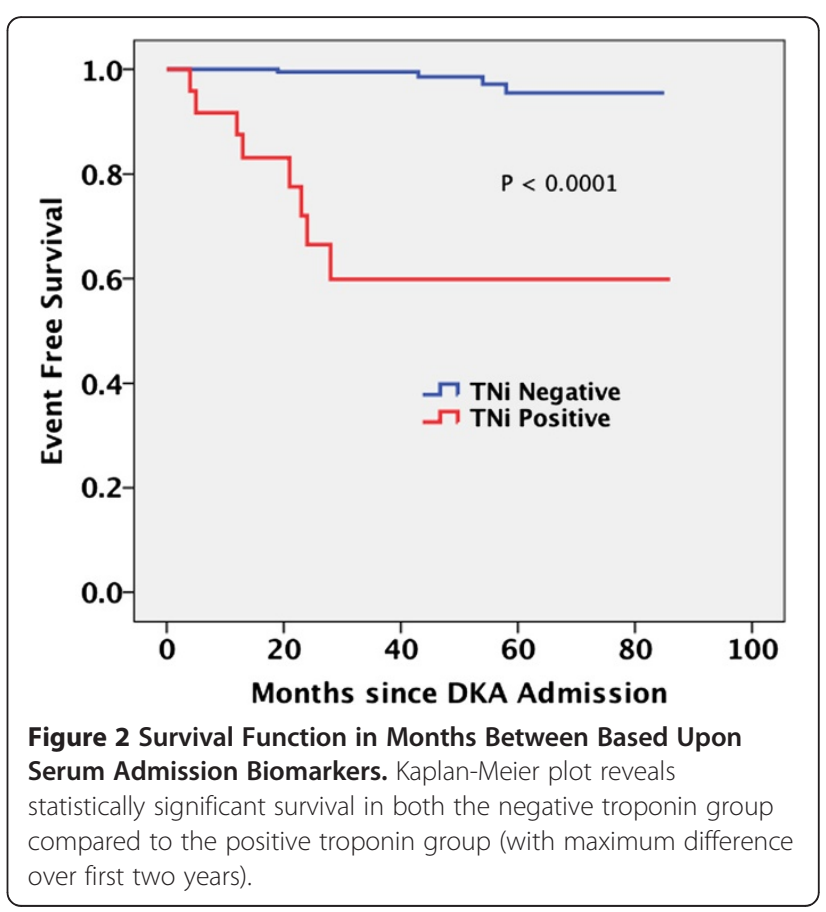


Table 3 Study outcomes amongst subjects enrolled based upon serum admission cTnl

\begin{tabular}{lccl}
\hline Variable & Normal cTnl & Elevated cTnl & P value \\
\hline MACE (\%) & 1.70 & 33.00 & $<0.001$ \\
\hline MI (\%) & 1.70 & 33.00 & $<0.001$ \\
\hline CABG (\%) & 0.00 & 0.00 & - \\
\hline PCl (\%) & 0.42 & 0.00 & $<0.001$ \\
\hline Death (\%) & 0.00 & 4.20 & $<0.001$ \\
\hline Mean Length of Hospital Stay (Days) & $5.73 \pm 0.37$ & $11.04 \pm 1.97$ & $<0.001$ \\
\hline
\end{tabular}

Abbreviations: $\mathrm{CAD}=$ Coronary Artery Disease; $\mathrm{CRI}=$ Chronic Renal Insufficiency; ESRD = End Stage Renal Disease; HTN = Hypertension.

phase, resulting in a complex between human cTnI and monoclonal anti-cTnI antibody. The Access AccuTni ${ }^{\mathrm{TM}}$ chemiluminescent immunoassay has a cTnI cutoff of $0.4 \mathrm{ng} / \mathrm{mL}$, this cutoff yields the most optimal sensitivity and specificity.

\section{Measurement of CK-MB}

Similar to cTnI, CK-MB was also measured with the Access AccuTni ${ }^{\text {TM }}$ chemiluminescent immunoassay, with a similar two monoclonal antibody system.

\section{Results}

Demographic characteristics of the patient population based upon serum admission cTnI and their clinical measures at admission are shown in Tables 1 and 2. Of 264 patients, 24 patients were found to have elevated cTnI. There were no statistically significant differences in age, sex or ethnic makeup identified amongst the studies participants when comparison was made based upon patients with normal versus elevated admission cTnI. Subjects with elevated admission serum cTnI had a greater prevalence of prior coronary artery disease, hypertension and chronic renal insufficiency when compared to their counterparts with normal levels. Blood glucose and serum admission $\mathrm{pH}$ were inversely proportional as seen in Figure 2.

Subjects with elevated serum cTnI had a significantly higher incidence of post discharge MACE when compared to normal subjects (Table 3). The increase resulted from a high incidence of myocardial infarction post discharge. Additionally, hospital length of stay was higher (Table 3) in the subjects with elevated admission serum cTnI when compared to their normal counterparts.

\section{Factors that predict elevated $\mathrm{cTn}$ l}

Table 4 shows the factors that made significant contributions to cTnI elevation. A history of coronary disease, low $\mathrm{pH}$ (less than 7.1), and elevated CK-MB levels were independent predictors for an elevated cTnI level.

\section{Factors that predict MACE}

Table 5 shows the contribution of clinical factors to risk for MACE following hospital discharge. Using multivariate logistic regression, a statistically significant relation was only found for an elevated admission serum cTnI, however $\mathrm{pH}$ also shows a strong trend toward influencing MACE. The other clinical factors listed in Table 5 do not show significant relationships with MACE. The odds ratio $(\mathrm{OR})$ for $\mathrm{pH}$ demonstrates an increased risk of MACE for decreased levels of $\mathrm{pH}$. Independent analysis of $\mathrm{pH}$ influence on MACE using univariate logistic regression identified a serum admission $\mathrm{pH}$ of less than 7.1 as statistically significant independent predictor for MACE.

Figure 3 shows a significant difference in event-free survival from MACE when comparing patients with and without elevated admission serum cTnI. The freedom from MACE is significantly lower in subjects who demonstrated elevated cTnI during hospitalization in the absence of evidence for an acute coronary syndrome.

Table 4 Multi-variable logistic regression for predicting elevations in cTnl

\begin{tabular}{|c|c|c|c|c|}
\hline Variable & $P$ value & O.R. & 95\% C.I. low & 95\% C.I. high \\
\hline Age & 0.484 & 0.984 & 0.940 & 1.030 \\
\hline$C A D$ & $<0.0001$ & 15.9 & 3.7 & 68.7 \\
\hline$\overline{\mathrm{pH}}$ & 0.027 & 0.047 & 0.003 & 0.706 \\
\hline$\overline{\mathrm{HTN}}$ & 0.419 & 1.70 & 0.471 & 6.10 \\
\hline Gender & 0.441 & 0.65 & 0.21 & 1.96 \\
\hline Chronic Renal Insufficiency & 0.680 & 0.71 & 0.14 & 3.70 \\
\hline Elevated Serum CK-MB & $<0.0001$ & 11.1 & 3.3 & 37.1 \\
\hline
\end{tabular}

Abbreviations: $\mathrm{CAD}=$ Coronary Artery Disease; $\mathrm{CK}-\mathrm{MB}=$ Creatine Kinase $-\mathrm{MB}$. 
Table 5 Multi-variable logistic regression for predicting MACE

\begin{tabular}{lcccc}
\hline Variable & P value & OR & 95\% C.I. low & 95\% C.I. high \\
\hline Prior History of CAD & 0.127 & 3.659 & -0.369 & 2.963 \\
\hline Elevated cTnl & 0.044 & 1.068 & 0.002 & 0.129 \\
\hline Hypertension & 0.085 & 5.312 & -0.228 & 3.567 \\
\hline Chronic Renal Insufficiency & 0.122 & 3.510 & -0.335 & 2.846 \\
\hline pH & 0.055 & 0.21 & -6.907 & 0.083 \\
\hline Age & 0.630 & 1.013 & -0.039 & 0.065 \\
\hline Gender & 0.395 & 0.543 & -2.017 & 0.796 \\
\hline Race & 0.329 & 0.422 & -2.590 & 0.567 \\
\hline Elevated CK-MB & 0.638 & 1.004 & -0.011 & \\
\hline Abbreviti
\end{tabular}

Abbreviations: $\mathrm{CAD}=$ Coronary Artery Disease; $\mathrm{CK}-\mathrm{MB}=$ Creatine Kinase - MB; Cardiac Troponin-I - cTnI.

\section{Factors that predict length of hospital stay}

Patients with an elevated serum cTnI at admission had longer lengths of stay. Between the two biomarkers, only $\mathrm{CK}-\mathrm{MB}$ was a statistically significant independent predictor for length of stay (Table 6).

\section{Discussion}

This study identified independent prognostic factors that predict elevations in serum admission cTnI, and demonstrated elevated admission serum CK-MB and c'TnI as prognostic for short and long term outcomes respectively. As a result, we gained insight into the clinical significance of elevated admission serum cardiac biomarkers in acute decompensated diabetes in the absence of clinically evident ACS. In the future, these data can be used to guide management.

An admission serum $\mathrm{pH}$ of less than 7.1 was demonstrated to be an independent prognostic factor for elevations in serum admission cTnI. To our knowledge, this is the first study to demonstrate a relationship between serum $\mathrm{pH}$ and elevated serum troponin. Our study supports the concept put forth by Moller et al., who noted that patients with elevated cTnI did not have angiographic evidence of coronary artery disease but had serum admission $\mathrm{pH}$ values of less than 6.9 [4].
What accounts for the correlation between cTnI and serum $\mathrm{pH}$ in the context of this study is unclear, and remains to be elucidated. A potential explanation highlights a complex dynamic between $\mathrm{pH}$ and intracellular calcium. As a result of severe acidemia, there is an increase in intracellular calcium which activates multiple biochemical pathways including proteolysis and myocardial stunning culminating in increased serum cTnI [23-28].

Approximately $40 \%$ of the patients with an elevated serum admission cTnI had a documented prior history of CAD. Regression analysis demonstrated a prior history of CAD as a prognostic factor for elevated cTnI. Acute decompensated diabetes is characterized by increased levels of counter-regulatory hormones which increase myocardial oxygen demand [14-16]. In such a population, the added effect of CAD likely impairs blood flow, exacerbating a supply-demand mismatch, resulting in myonecrosis and elevations in cTnI.

Logistic regression models identified an elevated admission serum cTnI as the only statistically significant variable for the long term composite outcome, MACE. Of interest is the finding that CK-MB was not correlated with the long term MACE outcome. Furthermore, an elevated admission serum cTnI proved to be a better predictor for MACE than a prior history of CAD $(p=0.127)$. MACE was primarily driven by myocardial infarction, thus

Table 6 Multi-variable linear regression for predicting length of hospital stay

\begin{tabular}{|c|c|c|c|c|}
\hline Variables Considered & B Coefficient & 95\% C.I. low & 95\% C.I. high & $P$ value \\
\hline$\overline{\text { Age }}$ & 0.071 & 0.023 & 0.120 & .004 \\
\hline Gender & -0.443 & -1.755 & .868 & .506 \\
\hline Chronic Renal Insufficiency & 0.686 & -1.643 & 3.016 & .562 \\
\hline $\mathrm{pH}$ & -2.363 & -6.359 & 1.634 & 0.245 \\
\hline Elevated cTni & -0.001 & -.108 & 0.106 & 0.986 \\
\hline Elevated CK-MB & 0.109 & 0.082 & 0.137 & 0.000 \\
\hline Hypertension & 0.466 & -0.962 & 1.893 & 0.521 \\
\hline Race & -0.613 & -1.494 & 0.268 & 0.172 \\
\hline
\end{tabular}

Abbreviations: CK-MB = Creatine Kinase - MB; Cardiac Troponin-I - cTnI. 


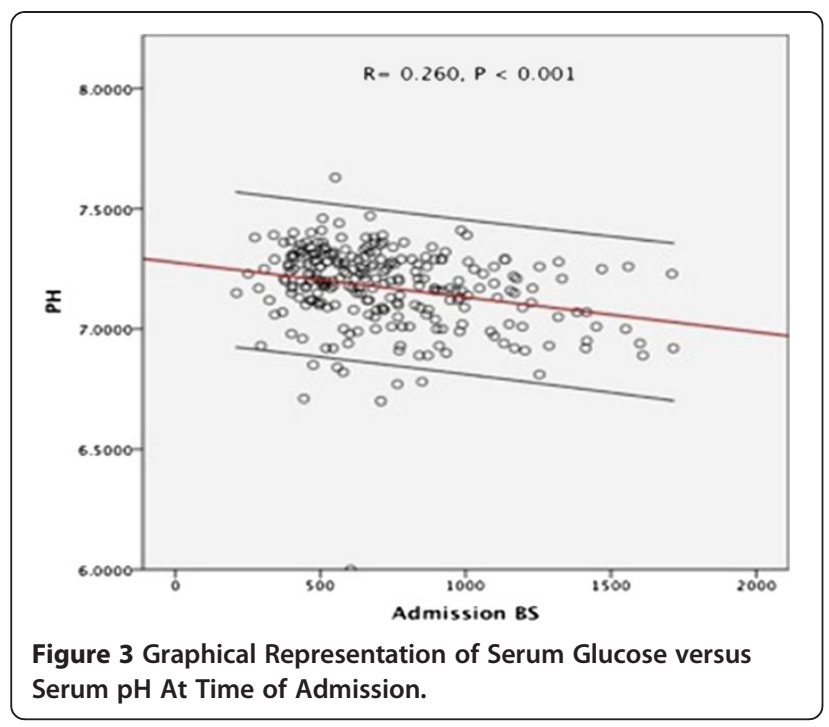

it was unexpected that a prior history of CAD was not a statistically significant independent predictor. More likely, MACE incidence represents multiple pathophysiologic mechanisms, independent of a prior history of CAD alone.

One factor, likely playing a major role in this cohort is insulin resistance. Recent literature has recognized more aggressive forms of type 2 diabetes marked by greater insulin resistance $[16,20,29-34]$. When these patients decompensate, they have increased production of ketoacids and more severe acidemia. Over time, insulin resistance leads to increased levels of pro-inflammatory cytokines like CRP and homocysteine that accelerate atherogenesis, plaque rupture, and MACE. This study noted an admission serum $\mathrm{pH}$ of less than 7.1 to trend toward statistical significance in an unadjusted logistic regression, and after adjusting for other variables, demonstrated a statistical significance for MACE. Demographically, patients with such aggressive forms of diabetes mellitus tend to be African American, in major urban cities. In comparison, $70 \%$ of the patients in our study were African Americans in a major urban city. The data suggest that patients in our study have a more aggressive form of diabetes mellitus that predisposes them to MACE independent of a prior history of CAD, and thus are at increased risk.

Concomitantly, in the context of non-diabetic patients status-post myocardial infarction, Knudsen et al. advance our premise. In an article published in 2010, they present a preponderance of evidence which highlights the connection between pro-inflammatory cytokines and deranged blood glucose control [35].

Studies by Hernandez et al. noted that $21 \%$ of diabetics have silent ischemia, and Zheng et al., suggest patients with diabetes have a chronic level of myocardial injury, and identified a correlation with blood glucose and elevated levels of serum hs-cTnT [36,37]. Populations such as this cohort, which stand at increased risk for adverse cardiac events underscore the need for future studies that further characterize a complex pathway.

Our findings corroborate those of Al-Mallah et al. who identified cTnI as prognostic for long term cardiovascular events in the context of DKA [38]. This study differed in that we demonstrated a different relationship of MACE to Troponin and to CK-MB. Further, our study identified independent prognostic variables that predict elevations in serum cTnI, lending an objective basis to explain their clinical significance. Further, we assessed short term outcomes, and identified CK-MB as an independent predictor for length of hospital stay. Thus, we define a novel role for CK-MB in the context of acute decompensated diabetes. Regarding patient characteristics, while both studies were relatively small, our study had nearly twice as many participants enrolled $(\mathrm{n}=264 \mathrm{v} \mathrm{n}=96)$ and our average length of follow up was nearly twice that of the prior study (40 months v 24 months).

\section{Study limitations}

This study was retrospective with a small sample size. In the future there is a need for larger multicenter prospective studies. Additionally, we lacked angiographic evidence at time of admission required to characterize coronary anatomy and thus patients were excluded based upon clinical information alone.

\section{Conclusions and clinical implications}

As a result of this study, we have identified independent prognostic factors which can help guide clinical management and predict elevations in cTnI, as well as short term and long term outcomes. While a prior history of CAD. Disease plays a key pathophysiologic role, the severity of acidemia appears to be equally important. cTnI and CK-MB should be measured in all patients with acute decompensated diabetes, if elevated, in the absence of clinically evident ACS, findings in this study identify a patient population that is at increased risk for a longer hospital stay in the short term, and increased risk for MACE post-discharge.

\section{Abbreviations \\ ACS: Acute coronary syndrome; cTnl: Cardiac troponin-l; CAD: Coronary artery disease; DM: Diabetes mellitus; TUH: Temple University Hospital; HHNK: Hyperosmolar hyperglycemic non-ketotic syndrome; MACE: Major adverse cardiac event; ESRD: End stage renal disease; PCl: Percutaneous coronary intervention; $\mathrm{CABG}$ : Coronary artery bypass grafting; HTN: Hypertension; MB - CK-MB: Creatine kinase.}

\section{Competing interests}

None of the authors have competing interests to disclose.

\section{Authors' contributions}

AE worked to collect data, research background articles, and draft the initial version of the manuscript. FR worked to collect data, research background articles and provide key editorial input for subsequent drafts of the manuscript. MA initiated the experimental design, researched background 
articles, interpreted EKGs, provided key editorial input for subsequent drafts of the manuscript. AG worked to edit the collected data, provide key editorial input for subsequent drafts, and played a key role in analyzing the study results and was very active in drafting the initial discussion section. HK provided key insight into the final outcomes, study design, editorial review and final version of the manuscript. AK worked throughout all stages of the study to provide key insight regarding the study outcomes, interpreting data, researching background articles and validation of statistical analysis. $A B$ served as the principal investigator and worked in all stages of the study including statistical analysis, editorial review, and provided key insight regarding interpretation of the data. All contributions from authors involved were essential in the development of the manuscript. All authors read and approved the final manuscript.

\section{Author details}

${ }^{1}$ Cardiology Section, Temple University School of Medicine, Philadelphia, USA. ${ }^{2}$ Department of Internal Medicine, Temple University School of Medicine, Philadelphia, USA. ${ }^{3}$ Temple University Medical Center - Cardiology Section, 3401 North Broad Street, Room, Philadelphia, PA19140, USA.

\section{Received: 13 December 2012 Accepted: 19 December 2012}

Published: 27 December 2012

\section{References}

1. Atabek ME, Pirgon O, Oran B, Erkul I, Kurtoglu S: Increased cardiac troponin I concentration in diabetic ketoacidosis. J Pediatr Endocrinol Metab 2004, 17(8):1077-1082.

2. Geddes J, Deans KA, Cormack A, Motherwell D, Paterson K, O'Reilly DS, Fisher BM: Cardiac troponin I concentrations in people presenting with diabetic ketoacidosis. Ann Clin Biochem 2007, 44(Pt 4):391-393.

3. Hiramatsu S, Komori K, Mori E, Ogo A, Maruyama S, Kato S: A case of fulminant type 1 diabetes mellitus accompanied by myocarditis. Endocr $J$ 2011, 58(7):553-557.

4. Moller N, Foss AC, Gravholt CH, Mortensen UM, Poulsen SH, Mogensen CE: Myocardial injury with biomarker elevation in diabetic ketoacidosis. J Diabetes Complications 2005, 19(6):361-363.

5. Parekh N, Venkatesh B, Cross D, Leditschke A, Atherton J, Miles W, Winning A, Clague A, Rickard C: Cardiac troponin I predicts myocardial dysfunction in aneurysmal subarachnoid hemorrhage. J Am Coll Cardiol 2000, 36(4):1328-1335.

6. John J, Woodward DB, Wang Y, Yan SB, Fisher D, Kinasewitz GT, Heiselman D: Troponin-I as a prognosticator of mortality in severe sepsis patients. J Crit Care 2010, 25(2):270-275.

7. Kelley WE, Januzzi JL, Christenson RH: Increases of cardiac troponin in conditions other than acute coronary syndrome and heart failure. Clin Chem 2009, 55(12):2098-2112.

8. Khan NA, Hemmelgarn BR, Tonelli M, Thompson CR, Levin A: Prognostic value of troponin $\mathrm{T}$ and I among asymptomatic patients with end-stage renal disease: a meta-analysis. Circulation 2005, 112(20):3088-3096.

9. King DA, Codish S, Novack V, Barski L, Almog Y: The role of cardiac troponin I as a prognosticator in critically ill medical patients: a prospective observational cohort study. Crit Care 2005, 9(4):R390-5.

10. Mahajan N, Mehta Y, Rose M, Shani J, Lichstein E: Elevated troponin level is not synonymous with myocardial infarction. Int J Cardiol 2006, 111(3):442-449.

11. Pham MX, Whooley MA, Evans GT Jr, Liu C, Emadi H, Tong W, Murphy MC, Fleischmann KE: Prognostic value of low-level cardiac troponin-I elevations in patients without definite acute coronary syndromes. Am Heart J 2004, 148(5):776-782.

12. Babuin $L$, Vasile VC, Rio Perez JA, Alegria JR, Chai HS, Afessa B, Jaffe AS: Elevated cardiac troponin is an independent risk factor for short- and long-term mortality in medical intensive care unit patients. Crit Care Med 2008, 36(3):759-765.

13. Hamblin PS, Topliss DJ, Chosich N, Lording DW, Stockigt JR: Deaths associated with diabetic ketoacidosis and hyperosmolar coma. 1973-1988. Med J Aust 1989, 151(8):439-441-2. 444.

14. Kitabchi AE, Umpierrez GE, Miles JM, Fisher JN: Hyperglycemic crises in adult patients with diabetes. Diabetes Care 2009, 32(7):1335-1343.

15. Kitabchi AE, Umpierrez GE, Murphy MB, Barrett EJ, Kreisberg RA, Malone JI, Wall BM: Management of hyperglycemic crises in patients with diabetes. Diabetes Care 2001, 24(1):131-153.
16. Johnson DD, Palumbo PJ, Chu CP: Diabetic ketoacidosis in a communitybased population. Mayo Clin Proc 1980, 55(2):83-88.

17. National Diabetes Surveillance System; http://www.cdc.gov/diabetes/ statistics/index.htm.

18. Anderson JL, Adams CD, Antman EM, Bridges CR, Califf RM, Casey DE Jr, Chavey WE 2nd, Fesmire FM, Hochman JS, Levin TN, Lincoff AM, Peterson ED, Theroux P, Wenger NK, Wright RS, Smith SC Jr, Jacobs AK, Halperin JL, Hunt SA, Krumholz HM, Kushner FG, Lytle BW, Nishimura R, Ornato JP, Page RL, Riegel B, American College of Cardiology, American Heart Association Task Force on Practice Guidelines (Writing Committee to Revise the 2002 Guidelines for the Management of Patients With Unstable Angina/Non ST-Elevation Myocardial Infarction), American College of Emergency Physicians, Society for Cardiovascular Angiography and Interventions, Society of Thoracic Surgeons, American Association of Cardiovascular and Pulmonary Rehabilitation, Society for Academic Emergency Medicine: ACC/ AHA 2007 guidelines for the management of patients with unstable angina/non ST-elevation myocardial infarction: a report of the American College of Cardiology/American Heart Association Task Force on Practice Guidelines (Writing Committee to Revise the 2002 Guidelines for the Management of Patients With Unstable Angina/Non ST-Elevation Myocardial Infarction): developed in collaboration with the American College of Emergency Physicians, the Society for Cardiovascular Angiography and Interventions, and the Society of Thoracic Surgeons: endorsed by the American Association of Cardiovascular and Pulmonary Rehabilitation and the Society for Academic Emergency Medicine. Circulation 2007, 116(7):e148-304

19. Bonow RO, Smaha LA, Smith SC Jr, Mensah GA, Lenfant C: World Heart Day 2002: the international burden of cardiovascular disease: responding to the emerging global epidemic. Circulation 2002, 106(13):1602-1605.

20. Friedewald VE, Leiter LA, McGuire DK, Nesto RW, Roberts WC: The Editor's roundtable: diabetes mellitus and coronary heart disease. Am J Cardiol 2006, 98(6):842-856.

21. Thom T, Haase N, Rosamond W, Howard VJ, Rumsfeld J, Manolio T, Zheng ZJ, Flegal K, O'Donnell C, Kittner S, Lloyd-Jones D, Goff DC Jr, Hong Y, Adams R, Friday G, Furie K, Gorelick P, Kissela B, Marler J, Meigs J, Roger V, Sidney S, Sorlie P, Steinberger J, Wasserthiel-Smoller S, Wilson M, Wolf P, American Heart Association Statistics Committee and Stroke Statistics Subcommittee: Heart disease and stroke statistics-2006 update: a report from the American Heart Association Statistics Committee and Stroke Statistics Subcommittee. Circulation 2006, 113(6):e85-151.

22. Vaccaro O, Eberly LE, Neaton JD, Yang L, Riccardi G, Stamler J, Multiple Risk Factor Intervention Trial Research Group: Impact of diabetes and previous myocardial infarction on long-term survival: 25-year mortality follow-up of primary screenees of the Multiple Risk Factor Intervention Trial. Arch Intern Med 2004, 164(13):1438-1443.

23. Orchard $\mathrm{CH}$, Kentish JC: Effects of changes of $\mathrm{pH}$ on the contractile function of cardiac muscle. Am J Physiol 1990, 258(6 Pt 1):C967-81.

24. Di Lisa F, De Tullio R, Salamino F, Barbato R, Melloni E, Siliprandi N, Schiaffino S, Pontremoli S: Specific degradation of troponin T and I by mu-calpain and its modulation by substrate phosphorylation. Biochem $J$ 1995, 308(Pt 1):57-61.

25. Gao WD, Atar D, Backx PH, Marban E: Relationship between intracellular calcium and contractile force in stunned myocardium. Direct evidence for decreased myofilament $\mathrm{Ca} 2+$ responsiveness and altered diastolic function in intact ventricular muscle. Circ Res 1995, 76(6):1036-1048.

26. Gao WD, Atar D, Liu Y, Perez NG, Murphy AM, Marban E: Role of troponin proteolysis in the pathogenesis of stunned myocardium. Circ Res 1997, 80(3):393-399.

27. Gao WD, Liu Y, Mellgren R, Marban E: Intrinsic myofilament alterations underlying the decreased contractility of stunned myocardium. A consequence of Ca2 + -dependent proteolysis? Circ Res 1996, 78(3):455-465.

28. Dhalla NS, Saini HK, Tappia PS, Sethi R, Mengi SA, Gupta SK: Potential role and mechanisms of subcellular remodeling in cardiac dysfunction due to ischemic heart disease. J Cardiovasc Med (Hagerstown) 2007, 8(4):238-250.

29. Umpierrez GE: Ketosis-prone type 2 diabetes: time to revise the classification of diabetes. Diabetes Care 2006, 29(12):2755-2757.

30. Umpierrez GE, Smiley D, Kitabchi AE: Narrative review: ketosis-prone type 2 diabetes mellitus. Ann Intern Med 2006, 144(5):350-357.

31. Newton CA, Raskin P: Diabetic ketoacidosis in type 1 and type 2 diabetes mellitus: clinical and biochemical differences. Arch Intern Med 2004, 164(17):1925-1931. 
32. Balasubramanyam A, Garza G, Rodriguez L, Hampe CS, Gaur L, Lernmark A, Maldonado MR: Accuracy and predictive value of classification schemes for ketosis-prone diabetes. Diabetes Care 2006, 29(12):2575-2579.

33. Balasubramanyam A, Zern JW, Hyman DJ, Pavlik V: New profiles of diabetic ketoacidosis: type 1 vs type 2 diabetes and the effect of ethnicity. Arch Intern Med 1999, 159(19):2317-2322.

34. Choukem SP, Sobngwi E, Fetita LS, Boudou P, De Kerviler E, Boirie Y, Hainault I, Vexiau P, Mauvais-Jarvis F, Calvo F, Gautier JF: Multitissue insulin resistance despite near-normoglycemic remission in Africans with ketosis-prone diabetes. Diabetes Care 2008, 31(12):2332-2337.

35. Knudsen E, Seljeflot I, Michael A, Eritsland J, Mangschau A, Muller C, Arnesen $H$, Andersen G: Increased levels of CRP and MCP-1 are associated with previously unknown abnormal glucose regulation in patients with acute STEMI: a cohort study. Cardiovasc Diabetol 2010, 9(1):47.

36. Hernandez C, Candell-Riera J, Ciudin A, Francisco G, Aguade-Bruix S, Simo R: Prevalence and risk factors accounting for true silent myocardial ischemia: a pilot case-control study comparing type 2 diabetic with non-diabetic control subjects. Cardiovasc Diabetol 2011, 10(1):9.

37. Zheng J, Ye P, Luo L, Xiao W, Xu R, Wu H: Association between blood glucose levels and high-sensitivity cardiac troponin $\mathrm{T}$ in an overt cardiovascular disease-free community-based study. Diabetes Res Clin Pract 2012, 97(1):139-145.

38. Al-Mallah M, Zuberi O, Arida M, Kim HE: Positive troponin in diabetic ketoacidosis without evident acute coronary syndrome predicts adverse cardiac events. Clin Cardiol 2008, 31(2):67-71.

doi:10.1186/1475-2840-11-154

Cite this article as: Eubanks et al: Clinical significance of troponin

elevations in acute decompensated diabetes without clinical acute coronary syndrome. Cardiovascular Diabetology 2012 11:154.

\section{Submit your next manuscript to BioMed Central and take full advantage of:}

- Convenient online submission

- Thorough peer review

- No space constraints or color figure charges

- Immediate publication on acceptance

- Inclusion in PubMed, CAS, Scopus and Google Scholar

- Research which is freely available for redistribution 